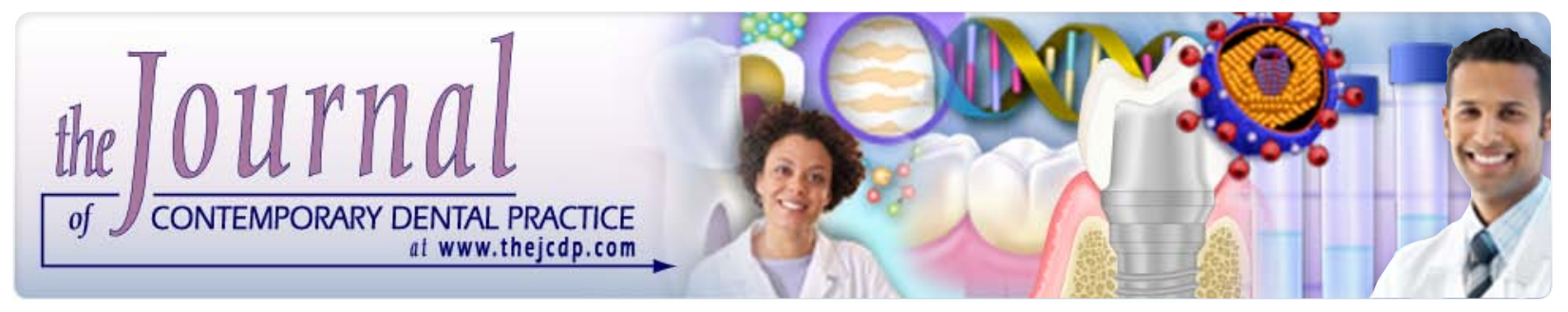

\title{
Direct Resin Composite Restorations versus Indirect Composite Inlays: One-Year Results
}

Juliano Sartori Mendonça, DDS, MS, PhD; Ranulfo Gianordoli Neto, DDS, MS, PhD; Sérgio Lima Santiago, DDS, MS, PhD; José Roberto Pereira Lauris, DDS, MS, PhD; Maria Fidela de Lima Navarro, DDS, MS, PhD; Ricardo Marins de Carvalho, DDS, PhD

\section{Abstract}

Aim: The aim of this study was to evaluate the clinical performance of direct resin composite restorations (Tetric Ceram-TC) and indirect composite inlays (Targis-TG) after 12 months.

Methods and Materials: Seventy-six Class I and II restorations (44 direct and 32 indirect) were inserted in premolars and molars with carious lesions or deficient restorations in 30 healthy patients according to the manufacturer's instructions. Each restoration was evaluated at baseline and after 12 months according to the modified USPHS criteria for color match (CM), marginal discoloration (MD), secondary caries (SC), anatomic form (AF), surface texture (ST), marginal integrity (MI), and pulp sensitivity (PS). Data were analyzed by Fisher and McNemar Chisquare tests.

Results: No secondary caries and no pulpal sensitivity were observed after 12 months. However, significant changes in marginal discoloration (MD) criteria could be detected between baseline and one-year results for both materials $(p<0.05)$. For marginal integrity $(\mathrm{MI})$ criteria, the differences between baseline and oneyear recall were statistically significant $(p<0.05)$. For marginal integrity (MI) criteria, Tetric Ceram (TC) showed results statistically superior to Targis (TG) in both observation periods $(p<0.05)$. No statistically significant changes in color match (CM), anatomic form (AF), or surface texture (ST) appeared during the observation periods $(p>0.05)$.

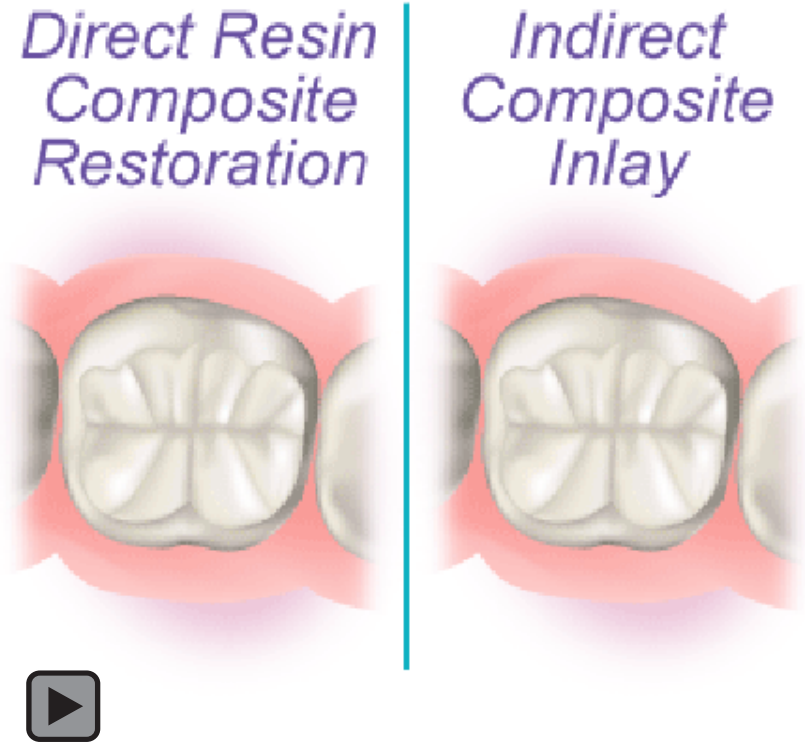

Conclusions: Direct resin composite restorations performed better than indirect composite inlays for marginal integrity, but all restorations were judged to be clinically acceptable.

Clinical Significance: Tetric Ceram direct restorations and Targis indirect inlays in posterior teeth provide satisfactory clinical performance and the comparison between them showed little difference after one year.

Keywords: Clinical evaluation, resin composite restorations, composite inlays, Tetric Ceram, Targis, direct restorations, indirect restorations

Citation: Mendonça JS, Neto RG, Santiago SL, Lauris JRP, Navarro MFL, Carvalho RM. Direct Resin Composite Restorations versus Indirect 
Composite Inlays: One-Year Results. J Contemp

Dent Pract [Internet]. 2010 May; 11(3):025-032.

Available from: http://www.thejcdp.com/journal/

view/volume11-issue3-santiago.

\section{Introduction}

Dental amalgam has been used successfully by dentists for decades. However, increasing numbers of patients and dentists opt for restorative materials other than amalgam for esthetic reasons. With the introduction of resin composites in the dental market in the 1960s, a new perspective appeared in restorative dentistry. Although the use of resin composites has grown considerably, many problems are associated with their use in the posterior region such as high polymerization shrinkage, gap formation, occlusal wear, and color instability. ${ }^{1-4}$ In vivo studies have reported poor wear resistance in contact areas, difficulty in generating proximal contour and contact, lack of marginal integrity, and postoperative sensitivity. ${ }^{3.4}$

To address these clinical challenges, manufacturers developed materials and techniques for the indirect construction of resin composite restorations..$^{2.5-7}$ Laboratory-processed resins generally differ only in their method of polymerization, which more completely cures the composites (it has a higher conversion rate from monomer to polymer). ${ }^{2}$ This has resulted in a reduction in the amount of intraoral polymerization shrinkage, better control of proximal restoration contours, improved control over marginal adaptation, enhanced physical properties of the restorative material, improved polishability, less water solubility, and increased hardness..$^{1-5,7-9}$ Disadvantages most frequently associated with the indirect technique are that it requires two appointments, there is technique sensitivity associated with managing impression materials and dies, it requires more time to place than the direct technique, and it is more costly compared to direct restorations. ${ }^{4.6}$

However, there are few clinical studies evaluating the clinical performance of indirect posterior resin restorations. Wendt and Leinfelder ${ }^{10}$ conducted a three-year clinical trial that demonstrated the success of this procedure. They found that indirect heat-treated resin composite inlays performed better than conventional indirect light-cured resin

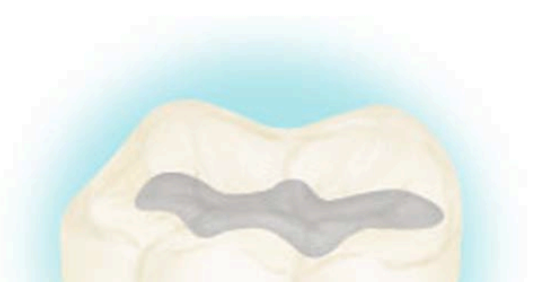

\section{amalgam restoration}

composite inlays in the categories of marginal integrity and interfacial staining. Other studies have reported the clinical success of direct and/ or indirect resin composite inlays and onlays over periods that vary from 1 to 11 years..$^{1-5,7,8,11-16}$ Van Dijken ${ }^{3}$ published results of a six-year clinical trial that included the evaluation of 100 direct resin composite inlays of which only six inlays have failed and needed replacement at the sixyear recall evaluation. Donly et al. ${ }^{7}$ evaluated the clinical performance of indirect posterior heat- and pressure- polymerized composite resins at seven years and compared to the performance of cast gold restorations. After seven years in situ, the restorations produced from an indirect posterior composite resin system were still clinically acceptable, particularly in premolars.

The purpose of this clinical research project was to evaluate the clinical performance of direct resin composite restorations (Tetric-Ceram/Ivoclar Vivadent) and indirect resin composite inlays (Targis/lvoclar Vivadent) in the posterior region of oral cavity after one year.

\section{Methods and Materials}

A total of 30 healthy patients ( 15 men and 15 women) were recruited for this study. Subjects ranged from 18 to 45 years of age (mean age 29.8). Health histories indicated that the patients were free of any major disease processes, and all intraoral and extraoral conditions were within normal limits, periodontally sound, and with normal occlusion. The study was explained to each individual recruited to include the need for evaluations at baseline and one year. Participation was voluntary for those selected and an informed consent form was obtained from all volunteers at the start of the study. Each individual had to 
need at least two posterior restorations and the criteria for selection were dental caries or failed restoration of amalgam and resin composite.

These teeth were examined clinically and radiographically to select premolars and molars that were free from periodontal diseases, pulpal involvement, and malocclusion. The ratio of Class I to Class II restorations and the ratio of premolars to molars were 1:2. All restored teeth were in occlusion and at least one surface of the Class II restoration was in proximal contact with the adjacent tooth.

\section{Clinical Procedures}

A total of 76 Class I and II restorations (44 direct and 32 indirect) were placed by the same operator. The teeth were carefully cleaned with a pumice-water slurry, rinsed with water, and air dried. Isolation of the preparation was achieved with a rubber dam. Care was taken to produce preparations with adequate dimensions and all Targis inlays were fabricated in a dental laboratory by the same dental laboratory technician.

For Tetric Ceram (Ivoclar Vivadent, Amherst, NY, USA) restorations, the walls of the preparations were slightly convergent with rounded internal line angles. The resulting isthmus was approximately one-third the width from facial to lingual cusp tips. Wherever possible, the gingival margins were placed in sound enamel and the cavosurface margins were not beveled. After preparation, calcium hydroxide cavity liner (Dycal, Kerr, Romulus, MI, USA) was placed at deep portions and undercuts were blocked out with a glassionomer liner (Vitrebond, 3M Dental, St. Paul, MN, USA). All tooth substrates and glass-ionomer lining material were etched with the IvoclarVivadent etching system for 15 seconds prior to rinsing with an air-water spray for 20 seconds. The single-bottle adhesive system (Excite, Ivoclar Vivadent) was applied according to the manufacturer's instructions and the compositeresin material (Tetric Ceram, Ivoclar Vivadent) was incrementally placed and light-cured for 40 seconds. A final finish was achieved after one week with carbide finishing burs and Ivoclar Vivadent polishers (Ivoclar Vivadent).

Targis (Ivoclar Vivadent) inlay preparations were made with the same principles applied for the direct resin composite restorations, except that the walls of the preparations were slightly divergent. A calcium hydroxide cavity liner (Dycal, Kerr) was placed in over the deepest dentine, and a glass ionomer base was used to eliminate irregularities and undercuts (Vitremer, 3M Dental). The inlay preparations were rinsed with water and dried before impressions were made. Tissue retraction was achieved with gingival retraction cord soaked in a hemostatic solution (Hemodent, Premier, Plymouth Meeting, PA, USA). Polyvinyl siloxane (Express, 3M Dental) impressions were made of the prepared arch to permit two casts to be poured from the same impression, and alginate (Jeltrate, Caulk/Dentsply, Milford, DE, USA) impressions were made of the opposing arch. Provisional restorations were fabricated from eugenol-free materials.

Indirect resin composite inlays were made according to the manufacturer's instructions. After laboratory fabrication, which included polymerizing the inlay on one plaster cast and then adjusting it on another stone cast, the provisional restoration was removed, the cavity preparation was cleaned, and the Targis restoration was tried in. Promixal and occlusal contacts were adjusted. All tooth substrates and glass-ionomer lining material were etched with the Ivoclar Vivadent etching system for 15 seconds prior to rinsing with an air-water spray for 20 seconds. Before cementation, the internal surfaces of the inlays were air-particle abraded with $25-\mu \mathrm{m}$ aluminum oxide. The internal surface of the restoration also was etched, silinated (Monobond S, Ivoclar Vivadent) and a thin layer of the adhesive system (Excite, Ivoclar Vivadent), was applied to both the restoration and the preparation without light-curing it. The inlays were cemented with dual resin composite cement (Variolink II, Ivoclar Vivadent). Excess material was then removed from the margins and a visible light-curing unit was used to polymerize the bonding and cementing resins for a total time of 120 seconds of light exposure (i.e., 40 seconds each bucally, lingually, and occlusally). Necessary occlusal adjustment was made after polymerization. Final finishing of the inlays was carried out with carbide finishing burs and Ivoclar Vivadent polishers before baseline evaluation at one week after placement.

Table 1 shows the restorative materials applied, their compositions and respective manufacturers. 


\section{Clinical Evaluation}

Restorations were evaluated at the baseline and after one year by two independent examiners with a mirror and explorer according to modified USPHS criteria ${ }^{17}$ (Table 2) for color match (CM), marginal discolorations (MD), secondary caries (SC), anatomic form (AF), surface texture (ST),

Table 1. Restorative materials used in the study.

\begin{tabular}{|l|l|l|}
\hline $\begin{array}{c}\text { Restorative } \\
\text { System }\end{array}$ & \multicolumn{1}{|c|}{ Manufacturer } & \multicolumn{1}{c|}{ Composition } \\
\hline Tetric Ceram & $\begin{array}{l}\text { Ivoclar Vivadent, } \\
\text { Schaan, Liechtenstein }\end{array}$ & $\begin{array}{l}\text { Bis-GMA, UDMA and TEG-DMA } \\
\text { Barium glass, Ba-Al-fluorosilicate glass, } \mathrm{Al}_{2} \mathrm{O}_{3}, \mathrm{YbF}_{3}, \\
\text { pyrogenic } \mathrm{SO}_{2} . \\
\text { Mean particle size: } 0.7 \mu \mathrm{m}\end{array}$ \\
\hline Targis & $\begin{array}{l}\text { Urethane dimethacrylate; Decanediol dymethacrylate } \\
\text { Bis-GMA; Barium glass, mixed oxide; Silicon dioxide; } \\
\text { stabilizers, catalysts, and pigments. } \\
\text { Sean particle size: 10-100nm }\end{array}$ \\
\hline
\end{tabular}

Table 2. Modified Ryge criteria used in this study.

\begin{tabular}{|c|c|c|}
\hline Criteria & Score & Characteristics \\
\hline \multirow{4}{*}{ Color matching } & A & Good color match \\
\hline & B & Slight mismatch not requiring replacement \\
\hline & C & Obvious mismatch, outside of normal range \\
\hline & $\mathrm{D}$ & Gross mismatch \\
\hline \multirow{4}{*}{ Marginal discolorations } & A & No discoloration evident \\
\hline & B & Slight staining, can be polished away \\
\hline & $\mathrm{C}$ & Obvious staining, cannot be polished away \\
\hline & $\mathrm{D}$ & Gross staining \\
\hline \multirow{2}{*}{ Secondary caries } & A & No caries \\
\hline & B & Secondary caries, location \\
\hline \multirow{3}{*}{ Anatomic form } & A & Completely intact with no perceptible loss of contour \\
\hline & B & Slight loss of contour not requiring replacement \\
\hline & C & Extensive loss of contour requiring replacement \\
\hline \multirow{4}{*}{ Surface texture } & A & Smooth surface \\
\hline & B & Slightly rough or pitted \\
\hline & C & Rough, cannot be refinished \\
\hline & $\mathrm{D}$ & Surface deeply pitted, irregular grooves \\
\hline \multirow{4}{*}{ Marginal integrity } & A & Excellent continuity at resin-tooth interface, explorer does not catch \\
\hline & B & Explorer catches, slight crevice margin, dentin or base not exposed \\
\hline & C & Obvious crevice at margin, dentin or base exposed \\
\hline & $\mathrm{D}$ & Restoration mobile, fractured, or missing \\
\hline \multirow{3}{*}{ Pulp sensitivity } & A & No sensitivity \\
\hline & B & Occasionally sensitive \\
\hline & C & Constantly sensitive \\
\hline
\end{tabular}


marginal integrity (MI), and pulp sensitivity (PS). The data collection form used at baseline and all recall periods was identical. Afterwards, the examiners compared their findings and, in case of a disagreement, they reached a consensus. Color photographs and bitewing radiographs were taken of each restoration at baseline and all recall appointments.

\section{Statistical Analysis}

Comparisons of ratings for restorations and between baseline and follow-up examinations were analyzed by Fischer and McNemar Chisquare tests for each category, with $p$ values $\leq$ 0.05 (95th percentile) considered to demonstrate statistically significant differences.

\section{Results}

The evaluated categories and evaluation technique followed modified USPHS criteria. The results of the clinical evaluations are shown in Table 3. The Alfa $(A)$ value indicated that conditions were clinically ideal, Bravo (B) ratings indicated clinical acceptability. Charlie (C) and Delta (D) ratings were not noted at baseline and one year.
All indirect composite inlays and direct resin composite restorations were considered as clinically acceptable at the one-year recall. One inlay was found to have a slight color mismatch and 12 inlays had slight marginal discoloration. Twenty-eight inlays were rated excellent in anatomic form and 30 were rated excellent in surface texture. Clinical signs of slight crevice margins were observed in 13 inlays. On the other hand, all direct resin restorations were considered excellent in color. Forty-one and 38 direct restorations were rated excellent in anatomic form and surface texture respectively. Seventeen restorations had discolored margins, but only five showed slight crevice margins. Figures 1 and 2 illustrate representative restorations over the course of the study.

Statistical analysis indicated significant changes in marginal discoloration (MD) criteria between baseline and one-year results for both materials $(p<0.05)$. For marginal integrity criteria, the differences between baseline and the one-year recall were statistically significant $(p<0.05)$. For marginal integrity criteria, Tetric Ceram had results that were statistically superior to Targis in both observation periods $(p<0.05)$. No statistically significant changes in color match, anatomic form, and surface texture appeared during the observation periods $(p>0.05)$ and no secondary caries were observed after one year.

Table 3. Clinical evaluation of direct resin composite restorations (Tetric Ceram) and indirect composite inlays (Targis) at baseline and one year.

\begin{tabular}{|c|c|c|c|c|c|c|c|c|c|}
\hline \multirow{2}{*}{ Criteria } & \multirow{2}{*}{ Ratio } & \multicolumn{4}{|c|}{ Tetric Ceram } & \multicolumn{4}{|c|}{ Targis } \\
\hline & & \multicolumn{2}{|c|}{ Baseline } & \multicolumn{2}{|c|}{1 year } & \multicolumn{2}{|c|}{ Baseline } & \multicolumn{2}{|c|}{1 year } \\
\hline \multirow{2}{*}{ Color match } & A & $100.0 \%$ & \multirow{2}{*}{ A } & $100.0 \%$ & \multirow{2}{*}{ A } & $93.75 \%$ & \multirow{2}{*}{ A } & $96.88 \%$ & \multirow{2}{*}{ A } \\
\hline & $B$ & - & & - & & $6.25 \%$ & & $3.12 \%$ & \\
\hline \multirow{2}{*}{ Marginal discoloration } & A & $86.67 \%$ & \multirow{2}{*}{ A } & $61.36 \%$ & \multirow{2}{*}{ B } & $93.75 \%$ & \multirow{2}{*}{ A } & $62.50 \%$ & \multirow{2}{*}{ B } \\
\hline & B & $13.33 \%$ & & $38.64 \%$ & & $6.25 \%$ & & $37.50 \%$ & \\
\hline \multirow{2}{*}{ Anatomic form } & A & $97.78 \%$ & \multirow{2}{*}{ A } & $93.18 \%$ & \multirow{2}{*}{ A } & $93.75 \%$ & \multirow{2}{*}{ A } & $87.50 \%$ & \multirow{2}{*}{ A } \\
\hline & B & $2.22 \%$ & & $6.82 \%$ & & $6.25 \%$ & & $12.50 \%$ & \\
\hline \multirow{2}{*}{ Surface texture } & A & $95.56 \%$ & \multirow{2}{*}{ A } & $86.36 \%$ & \multirow{2}{*}{ A } & $96.88 \%$ & \multirow{2}{*}{ A } & $93.75 \%$ & \multirow{2}{*}{ A } \\
\hline & B & $4.44 \%$ & & $13.64 \%$ & & $3.12 \%$ & & $6.25 \%$ & \\
\hline \multirow{2}{*}{ Marginal integrity } & A & $95.56 \%$ & \multirow{2}{*}{ A } & $88.64 \%$ & \multirow{2}{*}{ A } & $78.13 \%$ & \multirow{2}{*}{ B } & $59.38 \%$ & \multirow{2}{*}{$\mathrm{C}$} \\
\hline & $B$ & $4.44 \%$ & & $11.36 \%$ & & $21.87 \%$ & & $40.63 \%$ & \\
\hline \multirow{2}{*}{ Pulp sensitivity } & A & $93.34 \%$ & \multirow{2}{*}{ A } & $100.0 \%$ & \multirow{2}{*}{ A } & $84.38 \%$ & \multirow{2}{*}{ A } & $100.0 \%$ & \\
\hline & $B$ & $6.66 \%$ & & - & & $15.62 \%$ & & - & $A$ \\
\hline
\end{tabular}



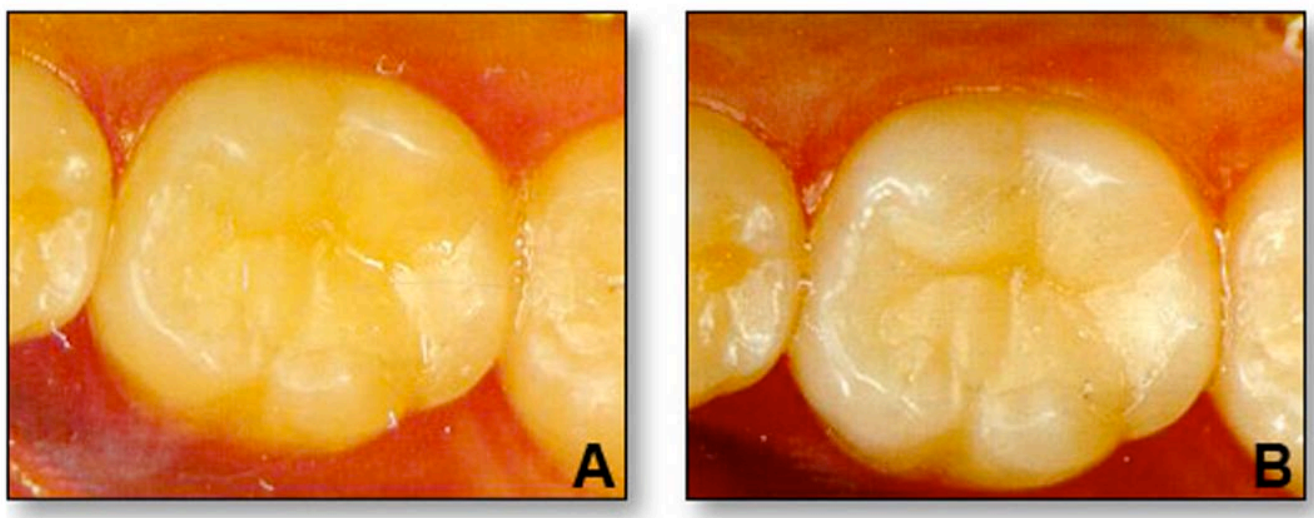

Figure 1. A. Clinical performance of Class I (O) Tetric Ceram restoration in 36 at baseline and $\mathbf{B}$. one-year recall.
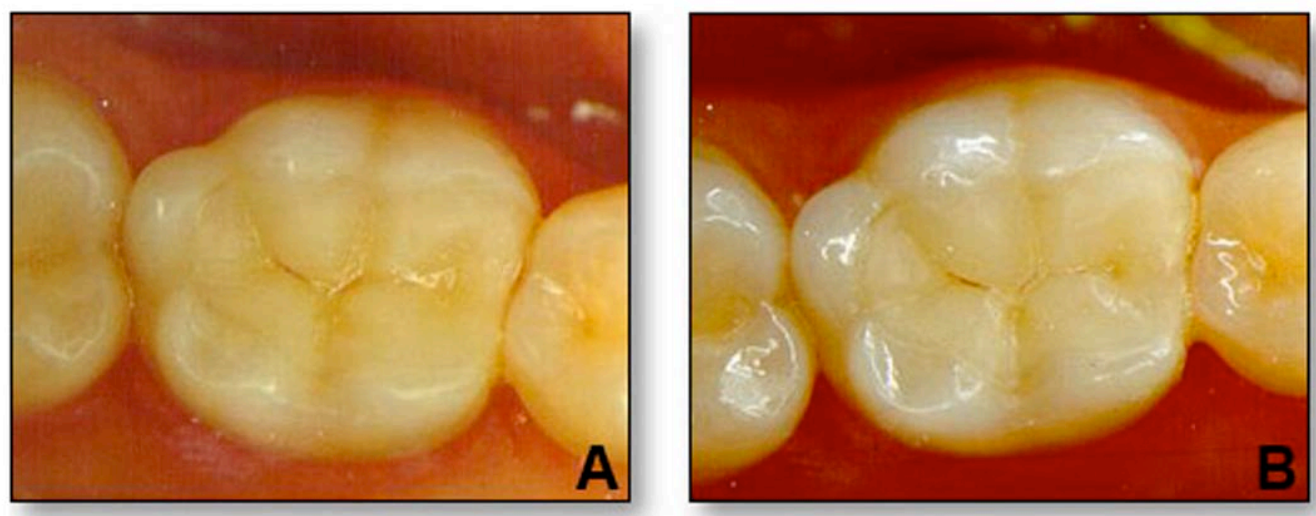

Figure 2. A. Clinical pertormance of Class II (MO) Targis inlay in 36 at baseline and B. oneyear recall.

Postoperative sensitivity improved during the course of the study. Initially, 15.62 percent of indirect composite inlays and 6.66 percent of direct resin composite restorations caused some postoperative sensitivity. This sensitivity declined to 0 percet for the teeth evaluated at one year.

\section{Discussion}

The sample size of 30 patients, the number of restorations, the ratio of Class I to Class II restorations, and the ratio of premolars to molars are in accordance with American Dental Association guidelines for testing a new material. ${ }^{18}$ All patients were available for recall at 12 months. This equates to a 100 percent recall rate, and it is expected to continue at a high recall level at subsequent recalls because Bauru Dental School has an agreement with the Bauru Military Police and a large number of the patients are police officers.
There was little difference in the clinical performance of direct resin composite restorations and indirect composite inlays. In view of the extra time required for preparing and fitting inlays, their use could be questioned in many cases where direct restorations are appropriate. However, it may be easier to obtain good proximal and occlusal contours using indirectly fabricated resin composite inlays made on removable dies. Another critical aspect in the use of indirect inlays is the removal of excess resin cement, particularly in the gingival margin area. Excess resin cement can be a clinical problem, resulting in plaque accumulation and gingival inflammation.

The resin composite inlay technique is an attempt to overcome some of the disadvantages of direct resin composite restorations. The most undesirable characteristic of the resin composite is still its polymerization shrinkage that could affect the marginal adaptation after restoration 
with subsequent secondary caries risk and postoperative sensitivity. ${ }^{3}$

The extraoral post-curing of the indirect resin composite inlay was introduced to enhance the physical and mechanical properties of the material, ${ }^{19-21}$ but no significant difference in wear resistance was found between non-heat- and heat-treated inlays after one- and three-year evaluations. ${ }^{1,20}$ Wear of the indirect composite inlay in this study, evaluated clinically by the USPHS criteria, showed that the wear rate is low and clinically acceptable in all patients after one year. Direct resin composite restorations showed no significant changes and no statistically significant differences in anatomic form appeared during the observation period ( $p>0.05)$ for both materials tested. This is in accordance with findings in other studies. ${ }^{2.4,11,22-24}$ According to Van Dijken, ${ }^{3}$ most of the wear of composite restorations occurs during the first 6 to 12 months and diminishes during the following years.

Moreover, signs of slight roughness were observed in only 6.25 percent of Targis inlays after one year. Despite the fact that no statistically significant difference was observed between indirect composite inlays and direct resin composite restorations for surface texture ( $p>0.05)$, Tetric Ceram was rated as 13.64 percent Bravo.

The heat polymerization also improves the marginal adaptation, probably by means of relaxation of residual material stress. ${ }^{3}$ Shrinkage of the inlay occurs before cementation, and the only clinical important shrinkage will occur in the thin cement layer. Feilzer et al. ${ }^{25,26}$ suggested that the $\mathrm{C}$-factor in the thin cement layers will be extremely large and the contraction equals the polymerization shrinkage in light-cured systems. Peutzfeld and Asmussen, ${ }^{27}$ on the other hand, showed in vitro that the increased wall-to-wall polymerization did not seem to be a problem. In this study, indirect composite inlays showed acceptable marginal integrity after one year. However, direct resin restorations showed results statistically superior $(p<0.05)$ to Targis inlays in both observation periods (baseline and one year). The difference in marginal integrity in the baseline could be explained by the indirect technique that provides a nonuniform cement layer at cavosurface margins. However, the marginal integrity for both materials was clinically acceptable with 100 percent Alpha and Bravo rates. Similarly, other clinical studies showed clinically acceptable adaptation of composite inlays after six months and 1, 1.5, 3, 3.5, 6, and 7 years. $\frac{2,3,5,7,11-14,22}{}$

After 12 months, the luting interface was detectable in various indirect inlays with a fine probe, which indicated slight wear of the resin cement. In many places a slightly underfilled margin was noted in occlusal areas because the wear resistance of the resin cement is lower than that of the inlay material. However, the slight abrasion of the luting agent had little influence on the clinical quality of the marginal adaptation because no marginal gaps were detected.

For marginal discoloration, there were statistically significant changes between baseline and the one-year recall for both resin composite materials $(p<0.05)$, but no significant difference was observed between indirect inlays and direct resin composite restorations ( $p>0.05)$. Slightly discolored margins are generally associated with marginal leakage and/or recurrent caries. However, no secondary caries or changes in pulp sensitivity were observed clinically and radiographically after one year, and these discolorations seemed to be located a minute distance from the teeth substrates, possibly at the interface of the resin cement and composite inlay or associated to the adhesive layer. Finally, the esthetics were excellent for both resin composite materials after 12 months because Alpha-ratings for color match were observed in 96.88 percent and 100 percent of indirect inlays and direct restorations, respectively.

Barone et al..${ }^{12}$ evaluated the clinical performance of composite inlays over a three-year period.

They found that composite inlays had a very high success rate (97.4 percent), and neither the size of the restorations nor the tooth type significantly affected the clinical outcome of the restorations.

Spreafico et al. ${ }^{13}$ found no significant differences for direct and semidirect hybrid composite restorations in posterior teeth with respect to marginal adaptation and clinical performance evaluated using modified USPHS parameters over 3.5 years. Wassell et al. ${ }^{15}$ reported that both inlays and conventional composite restorations 
complied with ADA specification minimum requirements for posterior composite restorations after five years and concluded that the direct inlay technique gave no clinical advantage over conventional incremental placement. Pallesen and Qvist ${ }^{16}$ evaluated the clinical performance of resin composite materials used for fillings and indirect inlays after 11 years and found failures more frequently in molar than premolar restorations. However, no significant difference between direct restorations and inlays or among the five types of resin composite materials was found. da Rosa Rodolpho et al. ${ }^{\frac{28}{}}$ showed that, after 17 years of evaluation, the clinical performance of posterior resin composite restoration was acceptable; however, in molars, Class II, and large restorations, the probability of failure was higher. In selected clinical situations, cuspal coverage of direct posterior composite restorations may represent a valid alternative to conventional indirect restorations. ${ }^{29}$ However, Bartlett and Sundaram ${ }^{30}$ suggested that the use of direct and indirect resin composites for restoring worn posterior teeth is contraindicated.

In this study, little difference was noted in the clinical performance of direct resin composite restorations and indirect composite inlays in posterior teeth after one year. Therefore, a longer observation period is indicated for substantiating the clinical performance of these resin composite systems.

\section{Conclusions}

On the basis of the results and despite the limitations of this study, it seems reasonable to conclude that all direct resin composite restorations and indirect composite inlays exhibited acceptable clinical performance over an evaluation period of one year.

\section{Clinical Significance}

Tetric Ceram direct restorations and Targis indirect inlays in posterior teeth provide satisfactory clinical performance and the comparison between them showed little difference after one year.

\section{References}

1. Wendt SL Jr, Leinfelder KF. The clinical evaluation of heat-treated composite resin inlays. J Am Dent Assoc. 1990; 120(2): 177-81.

2. Bessing $C$, Lundqvist P. A 1-year clinical examination of indirect composite resin inlays: a preliminary report. Quintessence Int. 1991; 22(2):153-7.

3. Van Dijken JW. A 6-year evaluation of a direct composite resin inlay/onlay system and glass ionomer cement-composite resin sandwich restorations. Acta Odontol Scand. 1994; 52(6):368-76.

4. Wassell RW, Walls AW, McCabe JF. Direct composite inlays versus conventional composite restorations: three-year clinical results. Br Dent J 1995; 179(9):343-9.

5. Gladys, S, Van Meerbeek B, Inokoshi S, Willems G, Braem M, Lambrechts P, Vanherle G. Clinical and semiquantitative marginal analysis of four tooth-coloured inlay systems at 3 years. J Dent. 1995; 23(6):329-38.

6. Kelsey WP 3rd, Triolo PT, Blankenau RJ, Kelsey MN, Ortmeier C, Hauser F. Bond strengths to enamel and dentin with indirect and direct resin composites. Am J Dent. 1996; 9(3):105-8.

7. Donly KJ, Jensen ME, Triolo P, Chan D. A clinical comparison of resin composite inlay and onlay posterior restorations and cast-gold restorations at 7 years. Quintessence Int. 1999; 30(3):163-8.

8. Watts DC, Wilson NH, Burke FJ. Indirect composite preparation width and depth and tooth fracture resistance. Am J Dent. 1995; 8(1):15-9.

9. Brown D. The status of indirect restorative dental materials. Dental Uptade. 1998; 25(1):23-8, 30-2, 34.

10. Wendt SL Jr, Leinfelder KF. Clinical evaluation of a heat-treated resin composite inlay: 3-year results. Am J Dent. 1992; 5(5):258-62.

11. Thordrup M, Isidor F, Hörsted-Bindslev P. A one-year clinical study of indirect and direct composite and ceramic inlays. Scand J Dent Res. 1994; 102(3):186-92.

12. Barone A, Derchi G, Rossi A, Marconcini S, Covani U. Longitudinal clinical evaluation of bonded composite inlays: a 3-year study. Quintessence Int. 2008; 39(1):65-71. 
13. Spreafico RC, Krejci I, Dietschi D. Clinical performance and marginal adaptation of class II direct and semidirect composite restorations over 3.5 years in vivo. J Dent 2005; 33(6):499-507.

14. Monaco C, Baldissara P, dall'Orologio GD, Scotti R. Short-term clinical evaluation of inlay and onlay restorations made with a ceromer. Int J Prosthodont. 2001; 14(1):81-6.

15. Wassell RW, Walls AW, McCabe JF. Direct composite inlays versus conventional composite restorations: 5-year follow-up. J Dent. 2000; 28(6):375-82.

16. Pallesen U, Qvist V. Composite resin fillings and inlays. An 11-year evaluation. Clin Oral Investig. 2003; 7(2):71-9.

17. Ryge G. Clinical criteria. Int Dent J. 1980; 30(4):347-58.

18. American Dental Association, Council on Scientific Affairs. Acceptance program guidelines: Restorative Materials. Chicago: ADA; 1996. p.1-9.

19. Wendt SL Jr. The effect of heat used as a secondary cure upon the physical properties of three composite resins. I. Diametral tensile strength, compressive strength, and marginal dimensional stability. Quintessence Int. 1987; 18(4):265-71.

20. Wendt SL Jr. The effect of heat used as a secondary cure upon the physical properties of three composite resins. II. Wear, hardness, and color stability. Quintessence Int. 1987; 18(5):251-65.

21. Khan AM, Satou N, Shintani H, Taira M, Wakasa K, Yamaki M. Effects of post-curing by heat on the mechanical properties of visible-light cured inlay composites. J Oral Rehabil. 1993; 20(6):605-14.
22. Krejci I, Lutz F, Gautschi L. Wear and marginal adaptation of composite resin inlays. J Prosthet Dent. 1994; 72(3):233-44.

23. Van Dijken JW, Sunnegårdh-Grönberg K. A four-year clinical evaluation of a highly filled hybrid resin composite in posterior cavities. J Adhes Dent. 2005; 7(4):343-9.

24. Gianordoli Neto R, Santiago SL, Mendonça JS, Passos VF, Lauris JRP, Navarro MF. One year clinical evaluation of two different types of composite resins in posterior teeth. J Contemp Dent Pract. 2008; 9(4):26-33.

25. Feilzer AJ, De Gee AJ, Davidson CL. Setting stress in composite resin in relation to configuration of the restoration. J Dent Res. 1987; 66(11):1636-9.

26. Feilzer AJ, De Gee AJ, Davidson CL. Increased wall-to-wall curing contraction in thin bonded resin layers. J Dent Res. 1989; 68(1):48-50.

27. Peutzfeldt A, Asmussen E. A comparison of accuracy in seating and gap formation for three inlay/onlay techniques. Oper Dent. 1990; 15(4):129-35.

28. da Rosa Rodolpho PA, Cenci MS, Donassollo TA, Loguércio AD, Demarco FF. A clinical evaluation of posterior composite restorations: 17-year findings. J Dent. 2006; 34(7):427-35.

29. Deliperi S, Bardwell DN. Clinical evaluation of direct cuspal coverage with posterior composite resin restorations. J Esthet Restor Dent. 2006; 18(5):256-67.

30. Bartlett D, Sundaram G. An up to 3-year randomized clinical study comparing indirect and direct resin composites used to restore worn posterior teeth. Int J Prosthodont. 2006; 19(6):613-7. 


\section{About the Authors}

Juliano Sartori Mendonça, DDS, MS, PhD

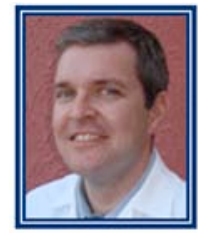

Dr. Mendonça is an adjunct professor in the Health Science Center at the University of Fortaleza in Fortaleza, CE, Brazil. His research interests include clinical trials and dental materials.

Ranulfo Gianordoli Neto, DDS, MS, PhD

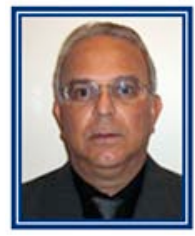

Dr. Gianordoli Neto is an adjunct professor in the Department of Operative Dentistry at the Federal University of Espírito Santo in Vitoria, ES, Brazil. His research interest is clinical trials.

Sérgio Lima Santiago, DDS, MS, PhD (Corresponding Author)

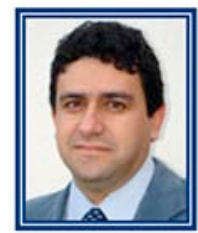

Dr. Santiago is an adjunct professor in the Department of Operative Dentistry at the Federal University of Ceará in Fortaleza, CE, Brazil, where he also serves as the cair of the postgraduate program. His research interests include clinical trials and dental materials.

e-mail: sergiosantiago@yahoo.com
José Roberto Pereira Lauris, DDS, MS, PhD

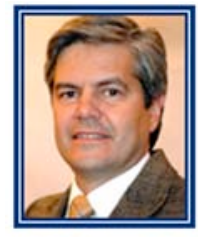

Dr. Lauris is an assistant professor in the Department of Pedodontics, Orthodontics and Social Dentistry of the Bauru School of Dentistry at the University of São Paulo in Bauru, SP, Brazil. He has been involved in research activities focusing on preventive dentistry.

Maria Fidela de Lima Navarro, DDS, MS, PhD

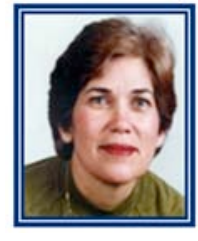

Dr. Navarro is a titular professor in the Department of Operative Dentistry, Endodontics and Dental Materials of the Bauru School of Dentistry at the University of São Paulo in Bauru, SP, Brazil. Her research interests include clinical trials, preventive dentistry, and dental materials.

Ricardo Marins de Carvalho, DDS, PhD

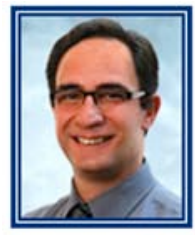

Dr. Carvalho is a associate professor in the Department of Prosthodontics of the Bauru School of Dentistry at the University of São Paulo in Bauru, SP, Brazil. His research interests include clinical trials and dental materials.

\section{Acknowledgements}

The authors gratefully acknowledge Mr. Hilton Riquieri for laboratorial support. This study was supported by Ivoclar Vivadent and CAPES/CNPq 300481/95-0. 